\title{
Non-random mating in Adalia bipunctata (the two-spot ladybird). II. Further tests for female mating preference
}

\author{
P. W. E. KEARNS, $\uparrow$ I. P. M. TOMLINSON $\ddagger$ C. J. VELTMAN* \& P. O’DONALD \\ * Department of Ecology, Massey University, Palmerston North, New Zealand, †OECD Environment Directorate, 2, rue \\ Andre-Pascal, 75775 Paris Cedex 16, France, $\ddagger$ Nuffield Department of Pathology, John Radcliffe Hospital, Oxford OX3 \\ 9DU, UK, and §Department of Genetics, University of Cambridge, Downing Street, Cambridge CB2 3EH, UK
}

\begin{abstract}
Tests for non-random mating in laboratory stocks of Adalia bipunctata showed that female twospot ladybirds from 'isofemale lines', which had formerly mated preferentially with melanic males, now mated at random. In an attempt to obtain new stocks in which females mated preferentially, we isolated 'isofemale lines' from a natural population at Keele, but we found no evidence of females mating preferentially within these stocks. We did, however, observe two interesting phenomena, not previously reported from Keele populations of Adalia bipunctata, or from laboratory stocks derived from the Keele population. Firstly, much of the variation in male mating success, which we observed, could be explained by the date on which the mating tests were carried out. Secondly, there was significant heterogeneity in sex ratios among some of the stocks. We discuss the potential importance of both these phenomena when designing experiments and interpreting data regarding non-random mating in Adalia bipunctata.
\end{abstract}

Keywords: Adalia bipunctata, female choice, non-random mating, polymorphisms, sex ratio, twospot ladybird.

\section{Introduction}

The two-spot ladybird (Adalia bipunctata) is highly polymorphic for colour and pattern, but most individuals can be classified as melanic or non-melanic. We have previously discussed the evidence for nonrandom mating between these morphs (Kearns et al., 1990 ), in most populations, there is either random mating or a general mating advantage in favour of melanics of either sex. In one population, however, from Keele, Staffordshire, some 'choosy' females were shown to have a genetic mating preference for melanic males (Majerus et al., 1982b). Later data from a Glasgow population supported the findings from Keele (O'Donald \& Majerus, 1988). Laboratory mating tests and selection experiments suggested that the female mating preference was under the control of a single locus (Majerus et al., 1986).

A number of further studies was suggested by the

Correspondence: C. J. Veltman, Department of Ecology, Massey University, Palmerston North, New Zealand. results of Majerus et al. (1982a, 1982b, 1986). We were interested in answering two questions in particular.

First, we wished to determine why female two-spots preferred melanic males. Our observations of ladybird behaviour suggested that females must often reject a number of suitors before exercising their preference; hence, they must incur significant costs in choosing a mate. Models of mate choice suggest that females must gain some compensatory selective advantage from choosing melanic males (for example, Tomlinson, 1989). It was our intention to discover the nature of this|advantage.

Second, melanism per se did not seem to be the feature which attracted females to males (O'Donald \& Majerus, 1987). We intended to find out what melanic males had that females preferred.

In order to solve these problems, we required a stock of Adalia bipunctata in which there was a high frequency of 'choosy' females that preferred melanic partners. In section (i) below, we report our failure not only to breed such a stock from the original stocks of Majerus et al. (1986), but also to find any preference at all in these ladybirds. This loss of preference necessi- 
tated further sampling of two-spots from the wild population at Keele in order to set up some new stocks of 'choosy' females. The results of these experiments are reported in sections (ii) and (iii).

\section{Methods and results}

\section{(i) New tests for preference in the original} high-preference lines

The aim of our first experiment was to confirm that the 'choosy' females from the original lines of Majerus et al. (1986) retained their preference for melanic males. It was our intention to use these ladybirds to answer our question about the nature of the female preference.

Majerus et al. (1982b, 1986) originally obtained female ladybirds with a preference for melanic males by means of a selection experiment. A laboratory population was established from a sample of wild twospots. The parents of subsequent generations were chosen by selecting mating pairs in which the male was melanic. After 10 generations of this selection, a number of 'isofemale lines' were set up, each of which was formed by the breeding of a large number of progeny from a single female.

The female progeny of each 'isofemale line' were then tested for their preference for melanic males. The method used was the 'formal mating test', in which 10 females were offered five melanic and five non-melanic males in a small mating chamber. Every $30 \mathrm{~min}$, all mating pairs were removed and replaced by males and females of their phenotype. Full descriptions of the methodology are given by Majerus et al. (1986) and Kearns et al. (1990).

The preference values measured from each of the 'isofemale lines' were found by Majerus et al. (1986) to fall into four groups: 'high preference' lines, in which over 90 per cent of females mated with melanic males; 'low' lines in which mating was at random; and two types of line with 'low' and 'high' intermediate levels of preference.

Four 'isofemale lines' (one of each type) were retested for preference by us in 1987, about 1 year after they were originally tested by Majerus et al. (1986). In the interim, the lines had been maintained in stock dishes under constant light at room temperature, and had been fed daily with aphids. Reproduction was stimulated by transferring adults to clean Petri dishes at 2-week intervals.

We used the same experimental method for testing as originally used by Majerus et al. (1986) (see above), except for our technique of sexing ladybirds. Not being confident of our ability to sex by eye, as Majerus et al. had done we introduced several animals into a clean dish a few days after emergence. When stable mating pairs had formed, they were removed and we identified males by extrusion of their parameters and their dominant position in copuli. Whilst they were in this position, the males were marked on one elytrum by a small blob of typists' correction fluid.

The results of our 'formal mating tests' showed that all four lines mated at random (Table 1). No preference for melanic males was detected in any line. Only in line $\mathrm{Z} 4$, one of the 'low lines', did our results not differ significantly from those found originally by Majerus $e t$ al. (1986).

Our results may have differed from those found previously for one or both of two reasons: either there had been strong selection pressure against 'choosy' females in the laboratory stocks in the interim period; or the experimental methods used, which had shown great repeatability in the past, were actually subject to inconsistency in their detection of preference.

\section{(ii) Attempt to repeat the 'isofemale line' experiment}

As we could no longer detect the female preference in the laboratory stocks, the Keele population of Adalia bipunctata was re-sampled in late August, 1987. We aimed to isolate a new set of 'isofemale lines' and thereby to find a 'choosy' stock.

A sample of 61 two-spots was collected. The frequency of melanics had declined to 9.8 from 31.6 per cent in August 1981 (Majerus et al. 1982a). This is consistent with the observed decline in melanic fre-

Table 1 Retesting of isofemale lines. Experiment 1 is that taken from Majerus et al. (1986) and Experiment 2 is our retest. Five typical ( $T$ ) and five melanic $(Q)$ males were placed in a mating chamber with ten females from the isofemale line under test. Mating pairs were removed every half hour and replaced with individuals of the same morph. The $\chi^{2}$ results test the deviation from randomness of the number of males mating and the $\chi^{2} i$ results test whether the Experiment 2 result differs significantly from Experiment 1

\begin{tabular}{|c|c|c|c|c|c|}
\hline \multirow{2}{*}{$\begin{array}{l}\text { Selected } \\
\text { line }\end{array}$} & \multirow{2}{*}{$\begin{array}{l}\text { Experiment } \\
\text { no. }\end{array}$} & \multicolumn{2}{|c|}{ No. mated males } & \multirow[b]{2}{*}{$\chi^{2}$} & \multirow[b]{2}{*}{$\chi^{2} i$} \\
\hline & & $\mathrm{Q}$ & $\mathrm{T}$ & & \\
\hline \multirow[t]{2}{*}{ Z4, low } & 1 & 51 & 48 & 0.091 & \\
\hline & 2 & 33 & 38 & 0.035 & 0.42 \\
\hline \multirow[t]{2}{*}{$Y 14,1-i$} & 1 & 149 & 74 & 12.612 & \\
\hline & 2 & 49 & 49 & 0 & 8.15 \\
\hline \multirow[t]{2}{*}{ Y9, h-i } & 1 & 150 & 50 & 50.000 & \\
\hline & 2 & 44 & 55 & 1.200 & 27.13 \\
\hline \multirow[t]{2}{*}{ Z35, high } & 1 & 203 & 7 & 182.933 & \\
\hline & 2 & 43 & 34 & 1.052 & 76.68 \\
\hline
\end{tabular}


quency in Birmingham (Brakefield \& Lees, 1987) and in South Wales (Tomlinson, 1989), but might also represent fluctuations in melanic frequency over the summer months. Our sample gave a greater than 5 per cent probability of not picking up a ladybird carrying a preference gene if the frequency of that gene was less than 0.02 . This compares with an estimated preference gene frequency of about 0.12 in the 1981 Keele sample (Majerus et al., 1982a). It would not have been surprising, however, if the frequency of the preference gene had declined as a result of its linkage disequilibrium with the preferred melanic character.

We were able to set up 'isofemale lines' from 13 females and carried out 'formal mating tests' on the female progeny in each line. The males used in all tests were, as in the past, a combined stock from all the 'isofemale lines'. Each male was therefore used a number of times to test different 'isofemale lines'. The results of the 'formal mating tests' are shown in Table 2a.

There was no overall deviation from random mating when the results from all the 'isofemale lines' were combined. This result concurred with the results from our mating tests on the original 'isofemale lines' and differed from the original finding of preference in the

Table 2 (a) Repeat of isofemale experiment. Method as given in caption to Table 1 . Lines were tested in the approximate chronological order shown, with some overlap between tests. (b) Further repeat of formal mating tests on isofemale line $11 \mathrm{E}$

\begin{tabular}{llll}
\hline & \multicolumn{2}{l}{$\begin{array}{l}\text { Number of } \\
\text { males mating }\end{array}$} & \\
\cline { 2 - 3 } Isofemale & \multicolumn{2}{l}{$\mathrm{T}$} & \multicolumn{1}{l}{$\chi^{2}$} \\
\hline line no. & $\mathrm{Q}$ & & \\
\hline (a) & & 39 & 5.238 \\
$11 \mathrm{E}$ & 62 & 42 & 0.103 \\
$11 \mathrm{H}$ & 45 & 43 & 0 \\
$11 \mathrm{~J}$ & 43 & 48 & 0 \\
$11 \mathrm{M}$ & 48 & 44 & 0.8 \\
$11 \mathrm{I}$ & 36 & 44 & 1.222 \\
$11 \mathrm{C}$ & 55 & 39 & 0.195 \\
$11 \mathrm{~F}$ & 43 & 48 & 2.036 \\
$11 \mathrm{~A}$ & 35 & 42 & 0.012 \\
$11 \mathrm{R}$ & 41 & 48 & 7.247 \\
$11 \mathrm{Q}$ & 25 & 24 & 2.632 \\
$11 \mathrm{~N}$ & 14 & 45 & 1.846 \\
$11 \mathrm{G}$ & 33 & 51 & 4.349 \\
$11 \mathrm{~K}$ & 32 & 557 & 1.894 \\
Total & 512 & &
\end{tabular}

Total heterogeneity $\chi^{2}=24.19$, d.f. $=12,0.01<P<0.05$

(b) $11 \mathrm{E}$ 44 48 0.174
Keele population (Majerus et al., 1986). It is possible, however, that we failed to sample or breed from an individual carrying a preference gene.

A new finding, however, was the significant heterogeneity in the data from these new 'isofemale lines': some lines showed excesses of either typical males (lines $11 \mathrm{Q}$ and $11 \mathrm{~K}$ ) or melanic males $(11 \mathrm{E}$ ) in mating pairs. The apparent mating advantage to typical males had never been observed before and suggested the possibility that there existed a previously undetected female preference for typica in addition to that for melanics.

Closer examination of the results reveals, however, that the first lines that were tested mated at random, or showed a slight advantage for melanic males. As the experiment progressed over several weeks, an advantage for typical males became apparent. It seems likely that this phenomenon, unnoticed in similar experiments previously, was an artifact of the lower frequency of melanics than typicals in the wild population and laboratory stocks. As we had fewer melanic than typical males, the former were maintained at lower densities in their culture dishes and may therefore have suffered less competition for food. Consequently, they may have been literally fitter than typica males, producing an excess of melanic males in the matings of lines $11 \mathrm{E}$ and $11 \mathrm{H}$ which were tested first. However, after a few of the 'isofemale lines' had been tested, each melanic males had been used repeatedly in mating. The more numerous typical males, however, had each mated a few times only. The melanic males may therefore have become 'worn out' slowly. Eventually they became under-represented in later mating tests (lines $11 \mathrm{Q}, 11 \mathrm{~N}, 11 \mathrm{G}$ and $11 \mathrm{~K}$ ).

To support this explanation for the heterogeneity in the mating data, the percentage of melanic males in mating pairs was regressed on the mean test date (a measure of how 'worn out' were the melanic males). Figure 1 shows that the regression analysis removes a significant amount of the variation among the isofemale lines'). An analysis of $\chi^{2}$ showed that the residual heterogeneity $\chi^{2}$ after fitting the line of regression was non-significant $\left(\chi^{2}=9.1\right.$, d.f. $\left.=11, P>0.5\right)$.

As a further experiment, we retested the isofemale line', 11E, that had exhibited a significant mating advantage to melanic males. This was necessary to determine whether the advantage was artifactual, or was the result of the female mating preference. A fresh set of males was used. Table $2 b$ shows that this line mated at random, which suggests that any male advantage arose by chance or as an experimental artifact.

The apparent dependence of male mating success on the mean test date could show the influence of some factor other than males being 'worn out' after many matings. Day length and male age are the most likely. 


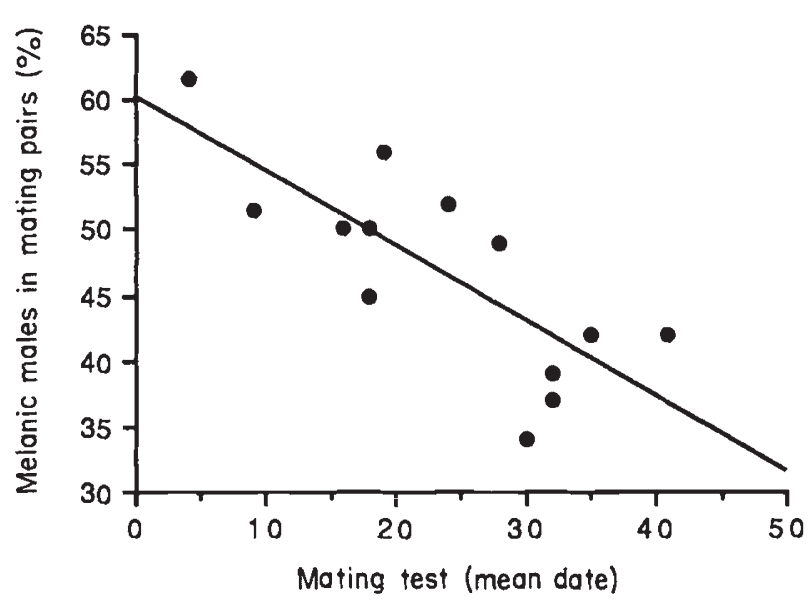

Fig. 1. Regression of the frequency of melanic males in matings of each isofemale line on the mean date of each formal mating test. Day '0' was 22/10/87.

Whatever the reason, we present two conclusions contrary to previous assumptions about non-random mating in Adalia bipunctata: first, the method of detecting preference can per se produce heterogeneity in the mating results; and second, the source of males used in mating tests is important for mating success.

\section{(iii) Attempt to select artificially for female preference and observations of variation in the sex ratio}

In a further attempt to identify two-spot females with a preference for melanic males, we performed a crude mass-selection experiment. Females and males surviving from our 'isofemale line' experiments were randomly placed in a mating chamber. When mating pairs had formed, they were removed. Four progeny lines were set up, bred from $\mathrm{Q} \times \mathrm{Q}, \mathrm{T} \times \mathrm{Q}, \mathrm{Q} \times \mathrm{T}$ and $\mathrm{T} \times \mathrm{T}$ matings (females first, $\mathrm{Q}=$ melanic morph, $\mathrm{T}=$ typical morph). The former two lines had been effectively selected for a preference in favour of melanic males and the latter, for any preference for typica.

'Formal mating tests' on these four lines failed to reveal any female mating preference (Table 3). There was no significant overall deviation from random mating when the results from all four lines were combined $\left(\chi^{2}=1.64\right.$, d.f. $=1$, n.s. $)$, nor was there significant heterogeneity among the lines $\left(\chi^{2}=5.13\right.$, d.f. $=3$, n.s. $)$. The $\mathrm{Q} \times \mathrm{T}$ line showed a significant excess of typical males in mating pairs $\left(\chi^{2}=5.15\right.$, d.f. $\left.=1, P<0.05\right)$, but this may simply have been a chance effect.

These selection lines did, however, reveal an important potential source of error in searching for nonrandom mating: the sex ratio in the progeny from each of the four lines was heavily biased in favour of females, sometimes dramatically so. An excess of
Table 3 Results of formal mating tests on new selected lines. See caption to Table 1

\begin{tabular}{llll}
\hline & \multicolumn{2}{l}{ No. mated males } & \\
\cline { 2 - 3 } & $\mathrm{Q}$ & $\mathrm{T}$ & $\chi^{2}$ \\
\hline $\mathrm{Q} \times \mathrm{Q}$ & 40 & 40 & 0 \\
$\mathrm{~T} \times \mathrm{Q}$ & 39 & 42 & 0.111 \\
$\mathrm{Q} \times \mathrm{T}$ & 36 & 58 & 5.149 \\
$\mathrm{~T} \times \mathrm{T}$ & 78 & 69 & 0.551 \\
\cline { 2 - 3 } & 193 & 219 & 1.64 \\
\hline
\end{tabular}

Total heterogeneity $\chi^{2}=5.18$, d.f. $=3, P>0.10$.

Table 4 Numbers of males and females in each of the four selection lines. See caption to Table 1

\begin{tabular}{|c|c|c|c|c|c|c|c|c|}
\hline \multirow[t]{2}{*}{ Line } & \multicolumn{2}{|c|}{$\mathrm{T} \times \mathrm{T}$} & \multicolumn{2}{|c|}{$\mathrm{Q} \times \mathrm{T}$} & \multicolumn{2}{|c|}{$\mathrm{T} \times \mathrm{Q}$} & \multicolumn{2}{|c|}{$\mathrm{Q} \times \mathrm{Q}$} \\
\hline & $\mathrm{Q}$ & $\mathrm{T}$ & $\mathrm{Q}$ & $\mathrm{T}$ & $\mathrm{Q}$ & $\mathrm{T}$ & $\mathrm{Q}$ & $\mathrm{T}$ \\
\hline Females & 4 & 152 & 89 & 48 & 53 & 59 & 45 & 9 \\
\hline Males & 9 & 82 & 16 & 9 & 13 & 19 & 39 & 7 \\
\hline$\chi^{2}$ & 6.19 & & 0.0 & & & & & \\
\hline
\end{tabular}

females had been found in a wild sample of two-spots from South Wales (Tomlinson, 1989) and in samples of other ladybird species (Henderson \& Albrecht, 1988), but had not been reported when sexing was performed for 'formal mating tests' in the past (Majerus et al., 1982a, 1986; O'Donald et al., 1984; O’Donald \& Majerus, 1988; M. Majerus, personal communication).

The numbers of males and females of each morph in the selection lines are given in Table 4 and show the female excess. There was no significant overall association between morph and sex $\left(\chi^{2}=0.27\right.$, d.f. $=1$, $P>0.05)$, although there were fewer than expected male typicals in the $\mathrm{T} \times \mathrm{T}$ line (Table 4 ). Table 5 shows that there was: significant heterogeneity among the sex ratios observed in each of the four lines; a significant deviation from a 1:1 sex ratio in all lines except $Q \times Q$; and a significant overall deviation from a 1:1 sex ratio when data from all four lines were combined.

The discovery of the female bias in the sex ratio may have resulted from our sexing of two-spots by mating, rather than the sexing by eye used in the past. There is, however, no evidence from past studies to suggest that errors were made in sexing: certainly, mis-sexing of females as males might have given the false appearance of a female preference, but we should expect this 'preference' sometimes to have favoured typical as well as melanic males. 
Table 5 Heterogeneity in sex ratio between selection lines

\begin{tabular}{lccrl}
\hline Line & Males & Females & \multicolumn{1}{l}{$\chi^{2}$} & Sex ratio \\
\hline $\mathrm{T} \times \mathrm{T}$ & 91 & 156 & 17.1 & $1: 1.71$ \\
$\mathrm{Q} \times \mathrm{T}$ & 25 & 137 & 77.4 & $1: 5.48$ \\
$\mathrm{~T} \times \mathrm{Q}$ & 32 & 112 & 44.5 & $1: 3.50$ \\
$\mathrm{Q} \times \mathrm{Q}$ & 46 & 54 & 0.6 & $1: 1.17$ \\
Total & 194 & 459 & 107.5 & $1: 2.37$ \\
\hline
\end{tabular}

Total heterogeneity $\chi^{2}=38.4$, d.f. $=3, P<0.001$.

\section{Discussion}

A feature of previous studies of mating using the Keele population of Adalia bipunctata (Majerus et al., 1982a, 1982b, 1986; O'Donald et al., 1984) was the lack of heterogeneity in the experimental results. Not only was there close agreement between mating frequencies in the wild and in the laboratory but there was also consistency both between experiments to select for the female preference and within 'isofemale lines'. Indeed, the unambiguous identification of four types of 'isofemale line' with distinct levels of preference led to the hypothesis of a single dominant allele controlling female preference for melanic males.

In contrast, observations of significant mating heterogeneity were made during the present study. There were departures from random mating in our 'isofemale lines' but most heterogeneity in melanic male mating success could be explained by the mean date of the experiment. This observation shows that patterns of non-random mating can be generated by some factor(s) that are unlikely to be a simply inherited female preference. In fact, such a pattern of nonrandom mating, as we observed, is likely to be influenced heavily by the experimental design.

It is improbable that mis-sexing can consistently generate an apparent female sexual preference for melanic males. We believe, however, that our observations on the heterogeneity of sex ratio among stocks also emphasize the importance of experimental design. At best, the 'formal mating test' is prone to the accumulation of individuals which are not sexually 'competent', whether they are mis-sexed, 'worn out' or debilitated in some other way. If there is some association between morph and lack of sexual competence, then nonrandom mating will be observed.

Our reassessment of the evidence for non-random mating in two-spot ladybird populations (Kearns et al., 1990) showed, amongst other things, that there is variation among populations. Our studies here failed to demonstrate female preference for melanic males, in either the original or new laboratory lines; they also revealed the importance of experimental design when measuring non-random mating. When taken together, these observations lead us to question the existence of a simple preference allele influencing female mating behaviour. Certainly, there is no one explanation for all the observed mating data from Adalia bipunctata.

\section{Acknowledgements}

Financial support for this work was provided to the Department of Genetics, University of Cambridge by the Science and Engineering Research Council through grants (PWEK) and a Research Studentship (IPMT). CJV received support while working at the Department of Genetics, University of Cambridge: as the Ann Horton Visiting Research Fellow, Newnham College; as a British Council Scholar; and with a grant from the Prince and Princess of Wales Science Award.

\section{References}

BRAKEFIELD, P. M. AND LEes, o. R. 1987. Melanism in Adalia ladybirds and declining air pollution in Birmingham. Heredity, 59, 273-277.

HENDERSON, S. A. AND ALbRECHT, J. S. M. 1988. Abnormal and variable sex ratios in population samples of ladybirds. Biol. J. Linn. Soc, 35, 275-296.

KEARNS, P. W. E., TOMLINSON, I. P. M., O'DONALD, P. AND VELTMAN, C. J. 1990. Non-random mating in the two-spot ladybird (Adalia bipunctata): I. A reassessment of the evidence. Heredity, 65, 229-240.

MAJERUS, M. E. N., O'DONALD, P. AND WEIR, J. 1982a. Evidence for preferential mating in Adalia bipunctata. Heredity, 49, 37-49.

MAJERUS, M. E. N., O'DONALD, P. AND WEIR, J. 1982b. Female mating preference is genetic. Nature, 300, 521-523.

MAJERUS, M. E. N., O'DONALD, P., KEARNS, P. W. E. AND IRELAND, H. 1986. Genetics and the evolution of female choice. Nature, 321, 164-167.

o'DONALD, P., DERRICK, M., MAJERUS, M. E. N. AND WEIR, J. 1984. Population genetic theory of the assortative mating, sexual selection and natural selection of the two-spot ladybird, Adalia bipunctata. Heredity, 52, 43-61.

o'DONALD, P. AND MAJERUS, M. E. N. 1987. Sexual selection models and the evolution of melanism in ladybirds. In: Feldman, M. W. (ed.) Modern Evolutionary Theory. Sinauer Associates, Sunderland, Massachusetts.

O'DONALD, P. AND MAJERUS, M. E. N. 1988. Frequency-dependent sexual selection. Proc. R. Soc. Lond. B., 319, 571-586.

TOMLINSON, I. P. M. 1989. Theoretical and Experimental Studies of the Evolution of Mate Choice. $\mathrm{PhD}$ thesis (unpublished). University of Cambridge. 